\title{
Simpósio sobre Educação Médica: uma experiência na Faculdade de Medicina de Botucatu
}

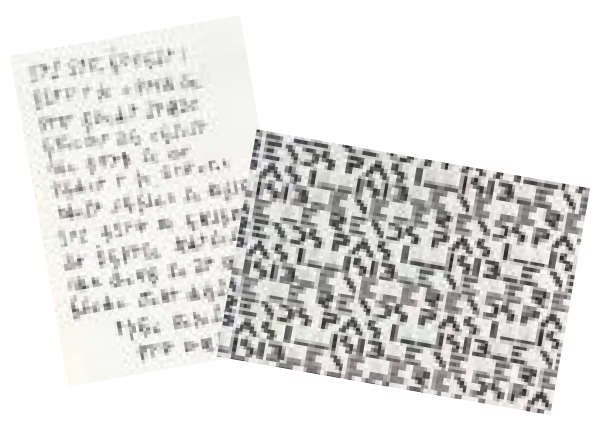

Aconteceu, em abril deste ano, o I Simpósio sobre Educação Médica da Faculdade de Medicina de Botucatu (FMB), organizado pelos alunos do Centro Acadêmico Pirajá da Silva (CAPS) desta Faculdade. A iniciativa surgiu da necessidade identificada pelos estudantes de realizar, dentro da Faculdade em que estudam, debates sobre Educação Médica em geral, como os que vêm acontecendo já há alguns anos em âmbito nacional (nos Congressos, Encontros, Oficinas). O evento teve o intuito de despertar o interesse e tornar mais amplo

o conhecimento da comunidade acadêmica acerca do assunto e, também, criar $e$ desenvolver discussões sobre Ensino Médico entre alunos, docentes $e$ administradores da

Faculdade, num espaço compartilhado $e$ aberto a todos.

A promoção do evento ainda teve por finalidade ampliar os debates sobre o curso de Medicina da FMB e as transformações que nele já estão ocorrendo, analisando-as frente

\author{
Juliana Maria Gera Abrão; Tatiana \\ Cristina Miranda de Oliveira; Silvia Pereira \\ Gulart; Liana Cunha Pupo; Enoch Quimberé \\ de Sá Barreto; Samuel de Moraes Ielo; Caio \\ Roberto Schwasty de Siqueira; Leonardo \\ Tagliari de Ângelo ${ }^{1}$
}

às mudanças didático-pedagógicas, estruturais e ideológicas propostas para a formação de médicos mais preparados para a atuação profissional no contexto social em que estão envolvidos.

A programação trouxe à tona temas gerais sobre Ensino Médico e outros específicos à realidade vivida no curso de Medicina da FMB.

O evento começou por refletir sobre o sentido da palavra "ensinar" de maneira a permitir a construção de conceitos referentes a métodos, proposições e posicionamentos em relação aos resultados do ensino médico atual. A discussão sobre "Reumanização do Ensino Médico" abordou o direcionamento dado à prática médica nos dias de hoje face aos avanços tecnológicos, às condições do Sistema de Saúde vigente no país e às cobranças e competições existentes no mercado de trabalho. O "PBL" (Problem Based Learning) e o "Currículo Nuclear" também foram temas de reflexão do

1 Alunos da Faculdade de Medicina de Botucatu; Departamento de Educação em Saúde do Centro Acadêmico Pirajá da Silva (CAPS), FMB/Unesp. <camed@uol.com.br> 
Seminário, trazendo discussões e debates que proporcionaram compreender melhor o rumo dado ao curso da FMB desde a mudança curricular ocorrida em 1996. Com o tema "Mudança Curricular na FMB", a atenção do debate centrou-se na problemática concreta vivida nesta Faculdade, começando por apresentar dados levantados $e$ analisados pelos estudantes do

CAPS acerca do grau de conhecimento em relação ao $\mathrm{PBL}$ dos alunos que estudam sob a nova proposta curricular. Para aprofundar os elementos do debate, aconteceram a exposição sobre "Regime Seriado", no qual se pauta o curso de Medicina da FMB, e a apresentação sobre pontuais mudanças desenvolvidas no curso de Saúde Pública. Esses temas embasaram as discussões que se seguiram sobre a mudança curricular, considerando seus motivos, suas formas de construção, principais diferenças em comparação ao currículo antigo, falhas, virtudes e possíveis razões para as dificuldades enfrentadas.

O "Internato na Graduação Médica" teve um espaço especial, devido ao fato de, no momento, os estudantes terem iniciado diversos questionamentos referentes aos cursos de $5^{\circ}$ e $6^{\circ}$ anos na FMB. O tema fechou o evento, trazendo argumentos $e$ críticas concretas sobre a formulação do Internato (excessiva carga horária), seus objetivos (especialização), a função do interno dentro do hospital e o compromisso da instituição com o ensino - questões já apontadas em outros espaços da vida universitária.

Dos cerca de 540 alunos e trezentos docentes existentes na FMB, 130 compareceram e participaram do evento, dos quais 2/3 eram estudantes. Embora não diminua a importância da realização do evento, a ausência de grande parte da comunidade acadêmica explicita parte das dificuldades enfrentadas neste momento de transição do modelo curricular do curso médico da FMB, em que a discussão do coletivo e a busca de respostas e construções novas se fazem necessárias.

Com essa iniciativa, os alunos do CAPS criam um espaço próprio e legítimo para discutir sua formação. Elogiado pelos participantes, o Seminário alcançou resultados positivos, no sentido de ampliar o repasse de informação $e$ as discussões sobre assuntos antes restritos a reuniões dos órgãos colegiados da FMB; identificar docentes e discentes engajados na proposta de transformar o ensino médico; levantar os entraves que impedem as mudanças; possibilitar a alunos, docentes $e$ representantes do Conselho de Curso de Graduação em Medicina, criarem coletivamente propostas de melhoria para o ensino na FMB. Ao final, algumas ações foram propostas, como: iniciar um núcleo de ensino médico na FMB; promover avaliações periódicas do curso, de modo a detectar suas deficiências e analisar os resultados de possíveis mudanças; realizar outros encontros semelhantes e dar continuidade a tais debates nas reuniões do CAPS, dos departamentos e dos órgãos colegiados da FMB.

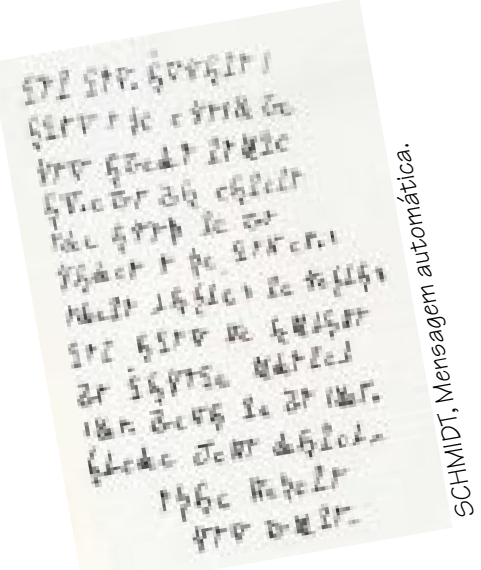

